\title{
O JORNAL ESCOLAR COMO RECURSO PEDAGÓGICO
}

\section{THE SCHOOL JOURNAL AS PEDAGOGICAL RESOURCE}

\author{
Andréa Larisse Castro Moura \\ Graduanda do Curso de Licenciatura em Letras das Faculdades Integradas Ipiranga \\ E-mail: andrealarisse.moura@gmail.com \\ Raimundo Araujo Tocantins \\ Professor das Faculdades Integradas Ipiranga \\ E-mail: raimundotocantins@bol.com.br.
}

Jornais são janelas de papel, através dessas janelas, o aluno pode atravessar as paredes da escola e entrar em contato com o mundo e com a atualidade. Jornais e revistas são, portanto, mediadores entre a escola e o mundo (FARIA, Maria Alice).

\section{RESUMO}

A escola representa muitas vezes a única oportunidade do jovem leitor estar em contato com o livro. É necessário propiciar de forma diversificada e interativa, um jeito de trazê-los ao mundo da leitura, contribuindo na sua forma de pensar, agir dentro de sua realidade. $\mathrm{O}$ estudo tem por objetivo analisar como se desenvolve a prática da leitura e escrita dos alunos por meio do desenvolvimento do seu pensamento crítico para a criação de textos, a partir do trabalho embasado em uma proposta didática e interativa, a qual estimula o uso de seus conhecimentos de mundo ao escrever as matérias. Assim, a utilização do Jornal contribuirá para transformar esse suporte em ferramenta pedagógica estimulante à leitura e a escrita, através do contato com conceitos básicos desse gênero e como suas características da teoria a prática da construção do Jornal escolar. Na Metodologia optou-se por uma pesquisa do Tipo Bibliográfica, numa abordagem básica e qualitativa e de embasamento fundamentado em referências de autores principalmente como Freinet, Faria Costa, Mikhail Bakhtin dentre outros, utilizando a concretização do ato através da leitura, discussão e escrita de textos. Os Resultados apontam que o jornal na escola possibilitará a realização de atos comunicativos, viabilizando esse aluno o contato direto com os diversos gêneros, incorporando a relação produtor - leitor de textos. Neste sentido infere-se que o trabalho com o jornal em sala de aula na prática, propiciará aos alunos um rico conhecimento cultural e social, tornando a prática da leitura e escrita uma atividade prazerosa e significativa.

Palavras-chave: Interação. Gêneros textuais. Jornal. Leitura. Escrita. 


\begin{abstract}
The school is often the only opportunity for the young reader being in contact with books. It is necessary to provide a way to bring them to the world of reading with a diversified and interactive manner, contributing in their form of thinking, acting within of their reality. The study aims to examine how to develop the practice of reading and writing of students by developing their critical thinking about the creation of texts from the work based in a didactic and interactive proposal, which encourages the using of their knowledge of world when write stories. Thus, the use of the newspaper contributes to transform this support in stimulating educational tool for reading and writing, through the contact with basic concepts of this genres and with their theory of characteristics of the practice of construction of the school newspaper. As Methodology we chose a bibliographic research, basic and qualitative in an approach and reasoned basis in author's references, primarily as Freinet, Faria Costa, Mikhail Bakhtin and others, using the realization of the act through reading, discussion and writing texts. The results point out that the school newspaper will enable the realization of communicative acts, enabling this student to have a direct contact with several genres, incorporating the producer-reader relationship. In this sense it is inferred that the works with newspaper in the classroom in practice will provide students with a rich cultural and social knowledge, making the practice of reading and writing a significative and pleasurable activity.
\end{abstract}

Keywords: Interaction. Genres. Newspaper. Reading. Writing.

\title{
I NTRODUÇÃO
}

O uso de jornais e da mídia em geral na educação seja fato recente na sala de aula, historicamente, desde a década de 1930 algumas iniciativas já ocorriam nesse sentido. Segundo Pavani (2007), Em 1932, o jornal New York Times, nos EUA criou um programa pioneiro para uso de jornais na escola. No Brasil na mesma época pode-se citar o educador Anísio Teixeira, dentro do movimento, Escola Nova, acreditava que usar a mídia impressa na sala de aula podia trazer diversos benefícios aos alunos.

Hoje, a leitura do jornal muda a perspectiva de muitos alunos que usam o jornal para melhorar a capacidade de compreensão do conteúdo escrito, bem como a capacidade de desenvolver o espirito crítico e de descobrir outras visões de mundo, na construção de significados e de identidades sociais. 
Tratar um jornal como um mero sistema de signos linguísticos reduz e limita o seu uso como proposta pedagógica. Sendo a cidadania o oposto da proposta acrítica, uma das formas de estimular a formação do cidadão crítico é justamente propor que o aluno participe ativamente na historia. Pontual (1999) acredita que ler uma noticia ou matéria de jornal é também poder olhar um pouco para si mesmo e, por conseguinte, torna-se mais consciente do seu papel no mundo. Levar o jornal para a sala de aula tem sido uma iniciativa comum a vários países do mundo e mais antiga do que se pode supor.

Do ponto de vista histórico, Conforme registra Adair (1995), “ainda nos EUA, já em 1932, surge no New York Times um programa de jornal para a educação: O News Paper in Educacion Program, reconhecido como marco na história dessas iniciativas, através da distribuição sistemática de suas edições nas escolas".

Ainda dentro das pesquisas de Adair (1995) em 1896, na França o jornal escolar foi iniciado pelo Educador Celestin Freinet que desenvolveu um método interessante baseado ou na experiência de vida e que concentrava a vivencia da aprendizagem por parte das crianças. Em 1924, Freinet agregou a técnica da impressão (tipografia) na sua prática docente, com seus alunos produzindo e imprimindo seus próprios textos. O intuito desse jornal era mostrar que o aluno pensa e articula em seu mundo, adquirindo uma consciência crítica e autônoma, estimulando não só as crianças, mas os jovens e os adultos que também participaram ao longo dessa jornada, a decodificar na prática o funcionamento da comunicação.

Segundo Pavani (1995), no Brasil, o Correio Popular, na cidade de Campinas (SP) foi o pioneiro neste caminho que hoje é povoado por um numero cada vez maior de contribuições. Era um projeto de incentivo ao uso do jornal na escola, em que disponibilizavam jornais para docentes com a finalidade de que utilizassem em sala de aula, todos os custos eram mantidos por uma empresa jornalística de São Paulo.

Este artigo tem como objetivo desenvolver a formação do pensamento crítico, através da leitura transportada para as páginas do jornal, tanto em forma de mural quanto impresso, através de pesquisas que contemplam a produção de diferentes formas de construções de jornais escolares, assim como toda a teoria que engloba esse processo. Reconhecendo as características dos gêneros que compõem um jornal, fazendo leituras e discussões de diversos temas em diferentes gêneros textuais, construindo diversos gêneros, dentro dos variados tipos de seções do jornal.

A pesquisa é composta de cinco seções. A seguir, na Fundamentação teórica, há uma subdivisão em alguns ramos nos quais são traçados alguns pressupostos teóricos sobre o que é o gênero textual de uma forma geral. Apresenta-se também o suporte jornal dentro da educação 
como auxilio no letramento, usado como base nesse estudo e ainda questões acerca do uso de diversos gêneros e suas funções dentro do jornal. Dentro da fase de análise de dados, algumas questões serão postas em ênfase dentro desse estudo: O que são os gêneros textuais? A importância do jornal escolar? O que ele busca trazer para a sala de aula?

\section{FUNDAMENTAÇÃO TEÓRICA:}

\subsection{GÊNEROS TEXTUAIS}

Para começar a falar do jornal escolar é necessário primeiramente conceituar de forma geral o que é um gênero. Segundo Marcuschi (2006, p. 25):

Os gêneros devem ser vistos na relação com as práticas sociais, os aspectos cognitivos, os interesses, as relações de poder, as tecnologias, as atividades discursivas e no interior da cultura. Eles mudam, fundem-se, misturam-se para manter sua identidade funcional com inovação organizacional.

Em que considera os gêneros textuais presentes em textos materializados, que circulam dentro dos discursos, uma espécie de sequência implícita aos textos postos em circulação nas práticas sociais com referência a Bakhtin (1997).

Embora esses PCNs de Língua Portuguesa (1997) coloquem os gêneros da imprensa como um dos principais conteúdos dos currículos escolares sabe-se muito pouco sobre quais são e como são esses gêneros. Para exemplificar o conceito de gêneros textuais citam-se: telefonema, carta comercial, reportagem jornalística, aula expositiva, notícias, horóscopo, piada, conversação espontânea, e-mail, bate-papo por computador e assim por diante. Entretanto na hora de utilizar esses gêneros na prática, dentro da escola, quase sempre são apenas praticados na aula de redação, como simples produção textual, como afirma Bagno (2002, p. 56) em sua publicação:

No tocante à produção textual escrita, as escolas brasileiras, em sua maioria, até hoje se restringem à prática da "redação", gênero textual que só existe na escola, não tendo, portanto nenhuma função sociocomunicativa relevante para a vida presente e futura do aprendiz.

Para modificar essa realidade, com base na teoria de Bakhtin, a escola deve trabalhar mais efetivamente com os gêneros do discurso, ora de forma explícita, ora não, fazendo a educação ser uma transmissora de conhecimento, de forma mais ou menos descontraída, mais ou menos burocratizada ou estereotipada como é refletido na posição Bakhtiniana (1997): Para 
entender um gênero especifico em relação ao jornal (como suporte) é necessário se ter uma noção de quais são os demais gêneros possíveis a serem tomados como base das atividades de ensino-aprendizagem.

Bakhtin (1997) cita dentro de seus conceitos que a linguagem permeia toda a vida social, exercendo um papel central na formação sociopolítica e nos sistemas ideológicos. Dentro dessa linguagem temos o gênero que é uma extensão da descendência de tipos de textos para a criação de pesquisas contendo certas características em comum, servindo de classificação para a reunião de textos. Para o autor, os gêneros do discurso, são uma espécie de flexibilidade ou instabilidade equivalente àquela prevista em documentos oficial anteriores para o próprio funcionamento da linguagem. Essa denominação 'gêneros textuais' não é consensual e poderia ser também 'gêneros discursivos' ou 'gêneros do discurso', como prefere chamar.

A noção de gênero, em Bakhtin (1997), pressupõe um enunciado concreto que inclui conteúdo temático, forma composicional, estilo, entonação expressiva, apontando para uma dimensão extra verbal que inclui os modos de produção e circulação, bem como os valores constituídos socialmente. No que diz respeito à concepção de linguagem, ainda pela visão do referido autor, o texto veicula a concepção de língua enquanto instrumento, propondo uma ação pedagógica que tenha a finalidade de instrumentalizar o educando no intuito de levá-lo a conviver de forma lúdica e, ao mesmo tempo, crítica com situações de produção e leitura de textos como forma de inserção social.

Na citação de Bakhtin (1997, p.302): “[...] Os gêneros do discurso organizam nossa fala da mesma maneira que a organizam as formas gramaticais. [...] Se não existissem os gêneros do discurso e se não os dominássemos, se tivéssemos de construir cada um de nossos enunciados, a comunicação verbal seria quase impossível", ou seja, os gêneros estão sempre ligados a algum tema e a um estilo. Ainda complementando este pensamento, é imprescindível o retorno a Bakhtin (2006, p. 262):

\footnotetext{
A riqueza e a variedade dos gêneros do discurso são infinitas, pois a variedade virtual da atividade humana é inesgotável, e cada esfera dessa atividade comporta um repertório de gêneros do discurso que vai diferenciando-se e ampliando-se à medida que a própria esfera se desenvolve e fica mais complexa. Cumpre salientar de um modo especial a heterogeneidade dos gêneros do discurso..
}

Essa heterogeneidade dos gêneros do discurso vai desde o oral ao escrito (desde o diálogo cotidiano, ao relato familiar, a escrita de uma carta ou até mesmo declarações públicas dentro de um sentido amplo: declarações sociais ou políticas). 
A teoria Bakhtiniana pretende demonstrar que o conceito de gênero envolve a essência da língua, a discursividade, considerando primordialmente a construção dos sentidos, tratando-se, dessa maneira, de gênero discursivo, o que vai além do gênero textual.

Percebe-se nesse estudo analisando as Orientações Curriculares, que embora em alguns momentos aponte para os gêneros discursivos, traz, predominantemente, a concepção de gênero textual, uma vez que a proposta é voltada para as analises linguísticas e textuais, com níveis separados de analise. A teoria de Bakhtin (1997) relata que o estudo da língua não prioriza nenhuma instância e a análise deve se efetuar tendo em vista os níveis linguísticos enunciativo - discursivo que comportam de forma indissociável o enunciado concreto.

\subsection{O TRABALHO EM SALA DE AULA COM OS GÊNEROS TEXTUAIS}

Espera-se com este trabalho, desenvolver entre os alunos a noção de texto como gênero textual, com o propósito de valorizar a reflexão e o senso crítico, focalizando o sentido e não apenas estruturas linguísticas. Para Marcuschi (2002), os gêneros se configuram em formas (escritas ou orais) que são historicamente situadas. Desse modo, o trabalho com esses textos em sala de aula parece mais significativo, visto que não são simplesmente tipificações textuais sem nenhum valor.

Ainda dentro do pensamento de Marcuschi (2002), os gêneros textuais são os textos que encontramos em nossa vida diária e que apresentam algumas propriedades funcionais e organizacionais, características realizadas. Ou seja, o reconhecimento da função e do processo de organização de tais estruturas é essencial para uma efetiva produção textual por parte do aluno. Em aulas tradicionais, o foco das produções parece ser justamente a avaliação de aspectos pontuais da gramática, enquanto que o estudo do gênero textual é ignorado.

O Kleiman \& Cavalcanti (2007, p 16) definem o uso dos gêneros textuais em sala de aula como:

[...] um conjunto de atividades que se origina de um interesse real na vida dos alunos e cuja realização envolve o uso da escrita, isto é, a leitura de textos que, de fato, circulam na sociedade e a produção de textos que serão lidos, em um trabalho coletivo de alunos com o professor, cada um segundo sua capacidade [...].

Isso significa que, seja qual for o objetivo do projeto, ele necessariamente será analisado e avaliado pelo professor conforme o seu potencial para mobilizar conhecimentos e recursos de uso da língua escrita. 
Kleiman \& Cavalcanti (2007) ainda defendem que a escola e os educadores devem trabalhar esse tipo de discurso midiático, para que os alunos tenham acesso a diversos tipos de leitura e assim consigam compreender o discurso de forma sintetizada. Para isso o caminho mais direto é o engajamento na atividade de linguagens significativas de natureza midiática (por exemplo, a produção de gêneros) para refletir e entender a construção desse discurso a partir de seus bastidores até a produção efetiva de uma notícia do jornal.

O trabalho com este grandioso suporte chamado jornal, permite o contato com a língua de forma viva e atual. $\mathrm{O}$ texto jornalístico é uma fonte que evidencia aspectos da realidade e recria o mundo conforme seu ponto de vista. Podemos perceber que em sua estrutura composicional, destaca-se: Quem?, Quê?, Onde?, Como, Quando? e Por quê. A escola deve usufruir dessas características para promover debates, pesquisas e, consequentemente, aprendizados, proporcionando uma nova compreensão da realidade.

\subsection{A UTILIZAÇÃO DO JORNAL COMO RECURSO PEDAGÓGICO}

De acordo com os autores pesquisados, percebemos que o trabalho com o jornal pode trazer subsídios para enriquecer o aprendizado em sala de aula, o seu uso de maneira planejada pelo docente pode reconstruir uma concepção de mundo e aguçar o senso crítico no público envolvido, frente às informações recebidas. Lopes (1989, p. 12), sob o ponto de vista pedagógico, diz que: “O jornal-laboratório deve ultrapassar a noção de ensaio experimental para se tornar uma iniciativa factível de serviço comunitário, prestando informação ou veiculando opiniões úteis para o comportamento do público leitor”. Podemos compreender, de acordo com as ideias acima mencionadas, que através deste recurso pedagógico, é possível estimular a leitura e a escrita e, desta forma, trabalhar a criatividade, para que o educando construa novas concepções em sala de aula. Consequentemente, isso fará com que ele se sinta responsável por este meio de comunicação dentro da escola.

Ao considerarmos a sala de aula como um local de comunicação, entendemos que tanto a leitura quanto a produção de textos são atividades indispensáveis em sua rotina. Segundo Herr (2001), ler é a possibilidade de estabelecer relações, seja com modos de pensar, personagens ou informações, de tal forma que seja possível compreendê-las. Então, produzir é a transmissão de informações para repartir com um público vasto ou restrito, impressões e ideias. Ou seja, Ler e Produzir são atos de comunicação, mas nem todos os alunos terão o desejo espontâneo de estabelecer essas relações. 
Segundo Tajra (2001, p. 131): “A produção de textos é um dos componentes mais importantes para a consolidação de nossos conhecimentos. Quem se expressa, se expressa em função de alguma situação e finalidade; quem conclui desenvolve uma visão crítica sobre algo". Assim, o uso do jornal como recurso didático, possibilita o trabalho com diversos textos, além de despertar nos alunos habilidades como: pesquisar, criticar, corrigir, etc.

O jornal na escola possibilita a realização de atos comunicativos, viabilizando esse aluno, o contato direto com os diversos gêneros textuais, e ao mesmo tempo, incorporando a relação produtor - leitor de textos, além de proporcionar um trabalho interdisciplinar, já que na elaboração do roteiro poderá ser distribuídas editoriais de outras áreas, além da Língua Portuguesa, usa-se um caderno sobre educação e preservação do meio ambiente mesclando conhecimentos de Biologia e Geografia, a Contação de histórias sobre as criações das cidades brasileiras, é um interessante tema para aulas de História e assim por diante.

Reforçando essa ideia, entre os benefícios de sua utilização na escola, o jornal se revela benéfico por possibilitar o contato com informações contextualizadas, deixando as aulas mais dinâmicas e relevantes para a formação crítica dos alunos. Nesse pensamento, Faria (2003, p.11) aponta que “(...) levar jornais/revistas para a sala de aula é trazer o mundo para dentro da escola. (...) Jornais e revistas são, portanto, mediadores entre a escola e o mundo". Dessa forma, os jornais se tornam boas alternativas para a ligação entre a escola e o dia a dia de alunos.

Faria (2003), centra sua preocupação principalmente na afirmação de que levar o jornal para a sala de aula é "Trazer o mundo para dentro da escola". Mas é preciso examinar com cuidado essa questão, uma vez que ao usar o jornal, o professor trabalha com a linguagem e, portanto, como um recorte da realidade ou mundo. Os maiores objetivos da produção do jornal em sala de aula, segundo a própria autora são: Educativo (contribuir para aperfeiçoar a educação) e Social (permitir o acesso do aluno ao projeto Jornal desde sua base teórica a construção propriamente dita).

Celestin Freinet (1977), afirma em suas pesquisas que existem vantagens de se trabalhar o jornal impresso como primeiramente a aprendizagem natural, sem esforço, da leitura e da escrita das palavras, dando um sentido permanente da construção de frases corretas e ensinando o sentido de responsabilidade pessoal e coletiva.

Erbolato (1991) assinala que o jornal impresso veio contribuir com a sociedade à medida que pode fornecer educação, cultura e informação durante anos, pela permanência e sobrevivências das páginas impressas de jornais e revistas. Explorar este universo implica desvendar e compreender a Arquitetura informal do jornal, ou seja, é identificar o papel de cada recurso que pode ser usado para a comunicação: Fotos, legendas, tabelas, manchetes etc., como elementos complementares e facilitadores do processo de escrita e leitura. 


\subsection{O USO DO JORNAL AUXILIANDO O LETRAMENTO}

A maioria dos projetos pedagógicos que envolvem o uso ou produção de jornal no ensino fundamental e médio tem seguido uma razão instrumental-utilitária. O jornal é um meio para consecução de objetos definidos, seja ela a alfabetização, o estimulo a leitura e a escrita ou ate mesmo o acesso a informações variadas.

Para entender o auxilio que o jornal traz ao letramento, cita-se a teoria acerca do Letramento que segundo Marques de Melo (1999) é entendido como um processo pelo qual os indivíduos se socializam através do pertencimento a um grupo e em troca participa na construção de praticas sociais dessas comunidades.

Lopes Rossi (2002) em suas pesquisas quanto ao uso dos gêneros textuais na sala de aula, mencionam a necessidade de se trabalhar os gêneros textuais, a fim de transformar o processo de leitura em pratica social, e assim estabelecer o processo de letramento. Já que o letramento pode ser definido por Soares (1998) como um estado ou condição de quem não só sabe ler e escrever, mas exerce as práticas sociais de leitura e escrita que circulam na sociedade em que vive. Propor-se educar para e com os meios de comunicação requer atenção nas análises, portanto, permanentes.

Ao produzir um jornal direcionado e cuidadosamente elaborado de forma especial para sua comunidade escolar, o professor estará incentivando esses Alunos - Editores ao hábito da leitura, a utilização da informação no seu dia a dia, a interpretação dos textos apurados e escritos com esses objetivos e, dessa forma, ajudará a ampliar o conhecimento de assuntos de real interesse para a vida dessa faixa estudantil, reforçado por Faria $(2006$, p, 12):

A leitura de jornal oferece, ainda, um contato direto com o texto escrito autêntico (e não com textos preparados apenas para serem usados na escola). Desenvolve e firma a capacidade leitora dos alunos; estimula a expressão escrita dos estudantes, que aprendem com o jornal a linguagem da comunicação para transmitir suas próprias mensagens e informações.

Teoricamente Bazerman (2005), enfatizam que o letramento não é um comportamento restrito a leitura e a escrita realizada na escola, mas trata-se de um conjunto de praticas construídas na vida diária em que há o acesso a conhecimentos e informações, escritas ou não, de uma determinada cultura. Além disso, reconstruir o processo de leitura, tanto de mundo como da escrita, transforma o educando em sujeito do mundo, capaz de modificá-lo positivamente. Confirmado no texto de Marcondes, Menezes e Toshimitsu (2003, p.151): 
Ler vários jornais propicia não apenas compreender a linguagem empregada, mas confrontar as informações. O objetivo é contrapor um jornal ao outro e sensibilizar o aluno para não acreditar deliberadamente em qualquer informação, sobretudo em dados, buscando ir além a suas leituras e fazendo perguntas sobre o que você leu: se é verdade integral ou parcial (...). o professor deve acompanhar as leituras dos alunos para verificar a veracidade dos confrontos.

As autoras Marcondes, Menezes e Toshimitsu (2003) ressaltam ainda que antes de fazer uma correção gramatical ou sintática, é importante garantir que o aluno produza textos que circulem também socialmente.

\subsection{O USO DO JORNAL E O SENSO CRÍTICO}

O jornal é um meio de comunicação de grande prestígio social que dissemina ideias e constrói significados. Pela diversidade dos seus textos, apresenta uma ampla variedade de gêneros discursivos que podem ser estudados na escola como forma de contribuir para a formação leitora do aluno, proporcionar a leitura de seu conteúdo é uma maneira de colocar os alunos em um debate mais amplo sobre ética, cidadania e valores.

Conforme, Freire (1987) comenta sobre a compreensão do texto a ser alcançada por sua leitura crítica implica a percepção das relações entre o texto e o contexto. Ainda dentro deste pensamento, Paulo Freire nos adverte para a necessidade de assumirmos uma postura vigilante contra todas as práticas de desumanização. Para tal, o saber-fazer da autorreflexão crítica o saber-ser da sabedoria exercitada, permanentemente, podem nos ajudar a fazer necessária leitura crítica das verdadeiras causas da degradação humana e da razão de ser do discurso fatalista da globalização.

Esse processo educativo iniciado na escola pode estender-se para outras esferas da vida do aluno, pois no entendimento de Ferrés (1996): A reflexão critica surgirá espontaneamente quando assistirem a imagens semelhantes fora da sala de aula, o que determina por estabelecer uma ponte entre a escola e os jornais, contribuindo a primeira para essa reflexão crítica e a segunda para um ensino mais significativo, já que o aprendizado quando se prolonga para fora da escola, transforma emoções em reflexões e o prazer em uma oportunidade a mais para uma análise crítica. Sobre este assunto Pavani (2002, p. 32) ressalta:

O objetivo geral da proposta não era outro senão o de levar os jovens não apenas a ler e a escrever, mas a buscar no jornal soluções e estímulos para a construção de apenas a ler um pensamento crítico, capacitando-os a encontrar soluções para os problemas que enfrentam. 
Tendo a preocupação da formação do leitor para compreender a estrutura social mostrada diariamente nas paginas dos periódicos. Ferrés (1996) complementa o discurso de Pavani quando cita ainda: Espera-se que esses estudantes sejam capazes de manter uma relação mais aprofundada com os meios de comunicação, deixando de lado um perfil passivo e conformado e exercendo uma postura questionadora, crítica e criteriosa.

\section{METODOLOGIA}

Para que essa pesquisa fosse desenvolvida, foi realizada uma pesquisa do Tipo Bibliográfica baseando-se em um estudo sobre os gêneros textuais, especialmente o jornal com todas as suas características, seu funcionamento, suas edições que de acordo com Minayo (1982) é aquela capaz de incorporar a questão do significado e da intencionalidade como inerentes aos atos, as relações e as estruturas sociais.

Uma vez que este trabalho é de suma importância para entender as concepções que o autor define acerca de estimular o incentivo à capacidade argumentativa e crítica do aluno perante as notícias, com a finalidade de posteriormente solicitar que o futuro escritor - aluno, concorde ou discorde de textos ou notícias através de argumentos convincentes.

Esta pesquisa de abordagem qualitativa e descritiva, com todo aporte teórico foi de suma importância para entender as ideias defendidas pelo autor no que se refere a estimular o incentivo à capacidade argumentativa e crítica perante o aluno, com a finalidade de instigar este aluno, a concordar ou discordar de textos ou notícias através de argumentos convincentes, já que os mesmos têm um vasto conhecimento de mundo, em que falta somente a lapidação dessas ideias organizadas no papel. Por esse entendimento, Soares (1998) vislumbra a possibilidade de que os educandos e educadores, ao vivenciarem todas as etapas de produção do jornal escolar, assumam e levem para avida a postura do repórter que observa, refletem e expressa o mundo.

Para que a pesquisa do Jornal Escolar tenha sucesso é necessário avaliar primeiramente como o autor discute como será a criação, assim como a manutenção deste jornal quando possivelmente estiver em prática, será importante sensibilizar professores e alunos, escolher coordenador, nomear líderes por turma para a equipe de jornalismo. Outro fator positivo que levaria o jornal para melhor aceitação na comunidade é depois de pronto, publicar a edição, pois assim disseminariam na comunidade escolar e no bairro envolvido, os valores e conhecimentos trabalhados em sala de aula.

Esta metodologia serve para propor uma reflexão e discussão de assuntos de interesse de um público jovem que se estimulado, evoluirá altamente seu pensamento crítico. Dinamizar 
o conteúdo fará com que os alunos se mostrem mais interessados na busca pelo saber, tendo a finalidade de promover a interdisciplinaridade de modo que alunos e professores possam envolver-se com o mesmo objetivo.

\section{RESULTADOS E DISCUSSÕES}

Para realização deste artigo foi feita uma pesquisa bibliográfica sobre o que são os gêneros textuais, a importância do suporte jornal na sala de aula como interação. Formando alunos capazes de escrever textos voltados para a sua sociedade com pensamentos mais críticos, corroborando com as afirmações sobre o uso dos jornais segundo Herr (2001) que aponta a formação de leitores capazes de dialogar com diferentes textos e a respectivos suportes textuais, produzido pelo aluno com o auxilio do professor, faz o aluno apropriar-se criticamente de diferentes modos de produção do discurso, contribuindo para que esses leitores se constituam também como autores.

Segundo a análise de textos estudados para esse projeto mostra que a construção de um jornal escolar em sala de aula pode resultar o maior contato com a realidade cotidiana, diferente dos livros didáticos que registram os fatos depois de algum período, assim confirmado por Herr (2001) que considera que o uso do jornal paralelamente ao do livro didático em sala de aula é uma necessidade de se colocar para o aluno, já que os livros registram somente depois de um discurso de tempo.

Percebe-se que a publicação do jornal é uma ferramenta para a escola disseminar, no espaço da comunidade, os conhecimentos trabalhados em sala de aula. Assim, o uso do jornal impresso na prática, contribuirá de forma positiva para a formação do aluno com um novo olhar crítico. Ensinando assim o mesmo, a entender a importância de seus conhecimentos dentro da sociedade. Assim confirmado através da concepção de Santos e Pinto (1992, p. 5):

O jornal estudantil não é um fim em si mesmo, mas um dos meios possíveis para o desenvolvimento de uma dinâmica geral na escola. Os jornais, por sua própria natureza, abordam um amplo leque de assuntos e, para isso, também apresentam uma grande diversidade de textos, sendo um dos instrumentos ideais da interdisciplinaridade.

As evidencias neste trabalho indicam que o jornal preencherá essa lacuna de informações entre situação que o aluno vivencia (realidade factual) e o fato histórico que o livro relata. 


\subsection{EIXO I: O USO DO SUPORTE JORNAL COMO MECANISMO DE APRENDIZAGEM:}

Segundo a análise de textos estudados para essa pesquisa, as discussões apresentadas apontam para a importância de conhecer os mecanismos que envolvem a formação das reportagens, manchetes e outras sessões, antes de chegar ao leitor, com a relevância de fazer uma boa interpretação, sendo, assim um escritor ativo e não o que simplesmente só recebe a mensagem sem fazer inferências sobre o assunto. A educação dos dias de hoje vem mostrando cada vez mais a necessidade da utilização de recursos e técnicas que proporcionam o despertar do aluno, com o intuito de criar uma visão crítica e consciente em relação às transformações da sociedade. É nesse contexto que o uso da impressa escrita em sala de aula como recurso para desenvolver e ampliar a compreensão histórica vem contribuir significativamente para a criação de um elo entre os conteúdos teóricos dos programas escolares com a realidade escolar e social, já que o professor ao trabalhar com a leitura e analise da imprensa escrita (o Jornal) possibilitará ao discente o contato com vários gêneros jornalísticos como: notícias, crônicas, charges, entrevistas e outros (Costa 2005).

\subsection{EIXO II: A IMPORTÂNCIA DA CRIAÇÃO DE CADA SEÇÃO:}

Jornais e revistas são recheados de textos com diferentes focos e interesses e são organizados em cadernos ou seções para melhor compreensão do leitor. De modo geral, encontramos os seguintes cadernos ou seções, em que cada tipo representa um interesse diferente do público leitor: classificados, editoriais, entrevista, cultura, esportes entre outros. Daí a importância de conhecer e ensinar sobre cada caderno:

\section{Classificados:}

Este caderno tem funções diversas: serve para vender, comprar, alugar. Serve também para anúncios de utilidades públicas, notas de falecimento e até para declarações de amor. O que o aluno pode absorver sesse caderno? O uso dos classificados poderá fazê-lo interagir com a sociedade escolar, à medida que consegue escrever e assim expressar seus interesses. 


\section{CLASSIFICADOS}

Dublê de filmes de açăo, precavido e com ataque de frescura, procura dublé para substituiflo em cenas mais perigosas.

Sujeito pe-de-chinelo deseja comprar sapato meia-sola.

Papel higiênico com vocaçầo para teatro oferece seu talento para diretor que lhe de um novo papel.
Dançarino deseja tornar-se alguem bem-sucedido. Motivo: cansou de dançar na vida.

Detetive iniciante busca ajuda para solucionar crime sem provas, testes. recuperação e dever de casa.

Vendo frango abatido Ele tả tristinho mas daqui a pouco passa.
Compro celular com viva-voz, comemoreolhoe eba-nariz.

Farmaceiutico carente de amor procura mulher para aplicar-lhe uma injeçăo de ânimo navida.

Bolsa utilizada em vagens deseja fazer um curso para se tornar alguém legal.

Motivo: cansou de ser chamada de mala.

\section{www.nadaver.com}

Figura 1: Classificados

Fonte: http://www.mundodastribos.com/classificados-tim-tim-por-tim-tim.html

\section{Editorial:}

É uma das partes mais importantes do jornal, é o espaço definido para que o grupo de escritores, redatores possam expressar sua opinião sobre um fato ou um tema comum entre toda sua escola. É aqui que a visão se faz livre do conceito de imparcialidade e da obrigação objetiva no ato de redigir o texto. Segundo Rabaca e Barbosa (1978, p. 267-268): o editorial assim como o caderno de opinião, é classificado como texto opinativo, pois expressa a opinião, o ponto de vista de uma pessoa, uma empresa ou de um governo. 
Pág-2 Terça-feira, 03 de Julho de 2012

\section{EDITORIAL}

Voltamos a circular nestas paragens codoenses depois de uma pausa de quase uma década. Vivíamos numa constante briga com o Poder Executivo devido a inconseqüência do prefeito daquele tempo, senhor Ricardo Archer, que debochava da imprensa de forma geral - no que encontrava apoio de certos de seus apaniguados -, e nós sempre nos posicionamos a favor da coletividade ajudando na produção do programa comandado pelo saudoso Julio Cesar Rodrigues ao mesmo tempo em que fazíamos o quadro Momento Social(que virou a coqueluche da cidade de Codó).

Hoje retornamos com este número que antecede a edição especial de abordagem ao aniversário de nossa cidade e para a qual chamo a atenção dos amigos empresários e profissionais liberais no sentido de nos ajudarem nessa nova jornada de levar a informação correta e imparcial aos munícipes deste que já foi o lugar de maior produção de arroz e algodão de todo o país verde-amarelo.

Desejamos a todos uma boa leitura e que Deus nos proteja hoje e sempre.

Figura 2 : Editorial

Fonte: http://correiocodoense.com.br/boa-noticia-o-jornal-esta-de-volta/

Entrevista:

É um gênero textual fundamentalmente dialogal, representado pela conversação de duas ou mais pessoas, o entrevistador e o entrevistado, para obter informações sobre assuntos de interesses públicos. 


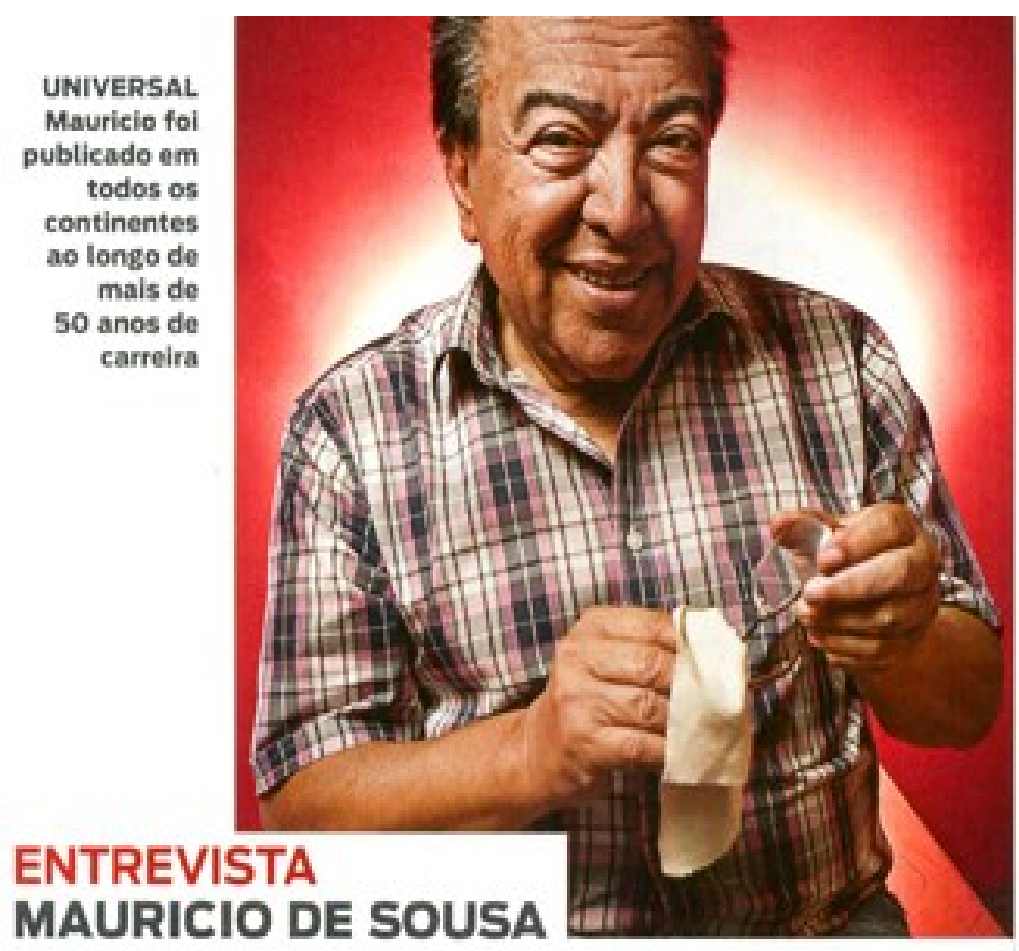

ISTOÉ-Como foi receber seu primeiro salário como cartunista?

Mauricio de Sousa - Era como se fosse um dinheiro diferente, com outro valor. Primeiro porque era menos do que eu ganhava como reporter - e esse era o lado preocupante. Segundo, porque sentia que era uma coisa que eu iria plantar, Planejei a minha primeira tirinha cuidadosamente. Tinha me preparado muito para criar as historias em quadrinhos e um sistema de redistribuiço em uma cadeia de jornais em todo o Brasil, como fazem os americanos. Se eles faziam lá, eu poderia fazer aqui.

ISTOE - E como o sr. se sentiut ao payar o primeino salário do seu primeiro funcionário?

Mauricio - Me senti satisfeito porque podia pagar (risos). Mas a dificuldade

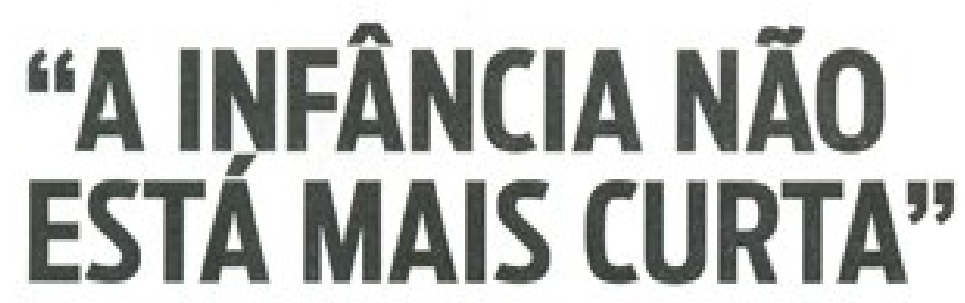

Aos 75 anos e um bilhão de gibis depois, o maior cartunista do Brasil relembra sua trajetória e revela segredos de sua tão conhecida matéria-prima: nossas crianças ali nào era financeira, material. Erat psicologica, já que eu fazia tudo sozi nho, era só um artista. Para mim, entregar o desenho para um auxiliar doia muito. Mas o pior foi passar o roteiro para outros criativos, ai foi duro. Depois de dez anos eu estava preparado para criar e produzir uma revista, a "Mónica". Acabamos de atingir o número 500 , mesmo com as mudanças de editora.

ISTOÉ - Como o st. conciliou o artista com o empreendedor?

\section{Figura 3: Entrevista}

Fonte: http://www.istoe.com.br/assuntos/entrevista/detalhe/172219 A+INFANCIA+NAO+ESTA+MAIS+CURTA+

\section{Entretenimento}

Este é um caderno com a funcionalidade de aproximar o leitor a diversos meios culturais: através dicas de livros, poesias e poemas de autorias próprias de alunos ou de autores famosos, cinema, palestras, shows. O design desta seção é composto de varias notas, cheias de imagens e quase sempre rica de cores com o objetivo de chamar atenção. Ainda segundo Rabaca e Barbosa (1978, p. 267-268): este caderno representa o caráter recreativo dos gêneros jornalísticos. Exemplos: os passatempos, as tirinhas de humor. 


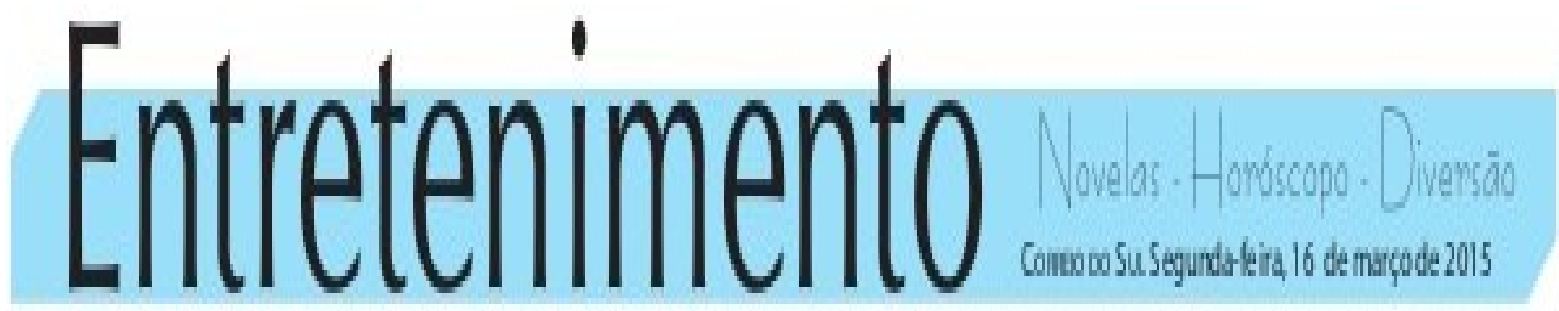

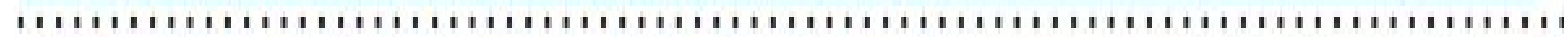

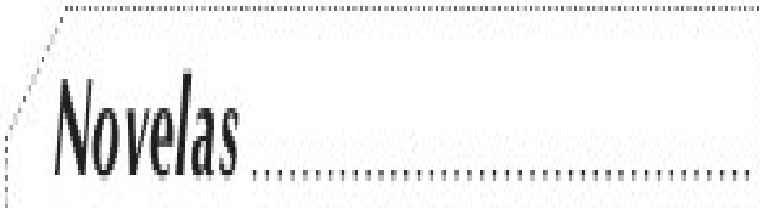

\section{setéf SeteVidas-18h}

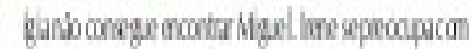

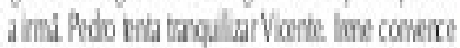

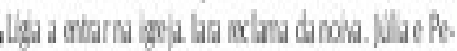

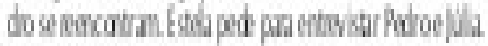

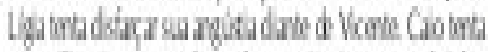

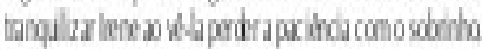

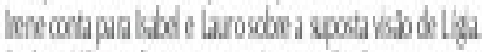
Hodo ơ

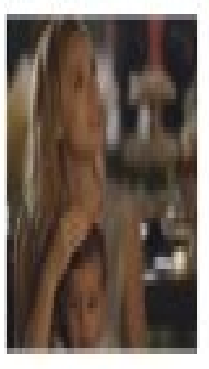

\section{$+4$

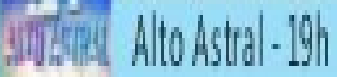

P

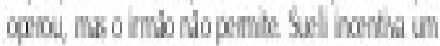

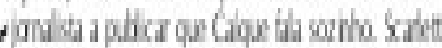

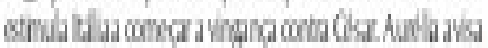

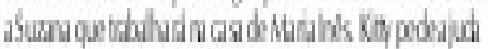

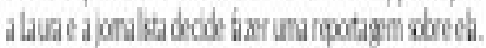

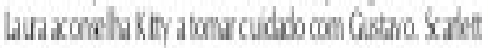

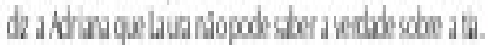

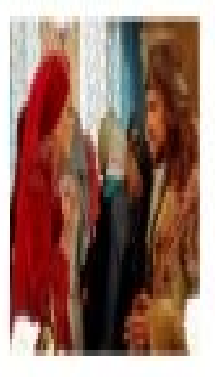

Figura 4: Página de Entretenimento

Fonte: http://pt.slideshare.net/correiodosul/jornal-digital-4627seg16032015

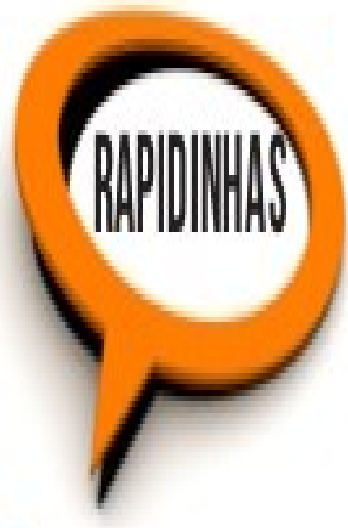

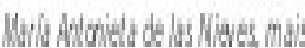

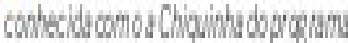

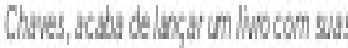

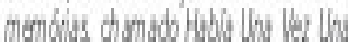

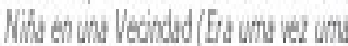

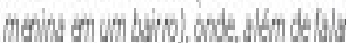

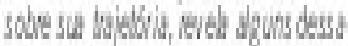

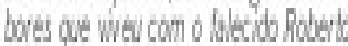

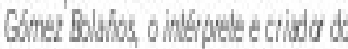
Chwis.

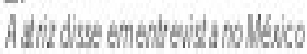

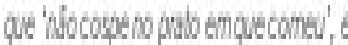

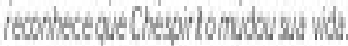

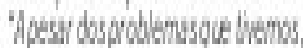

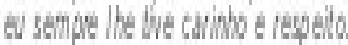

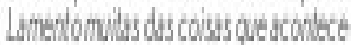

\section{Horóscopo}
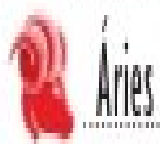

INIIIN

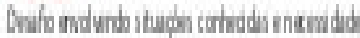

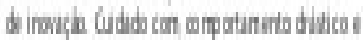

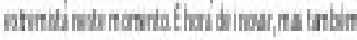

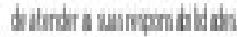

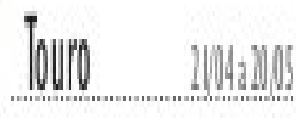

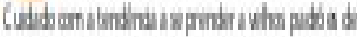

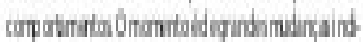

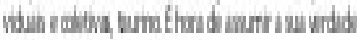

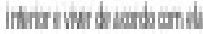

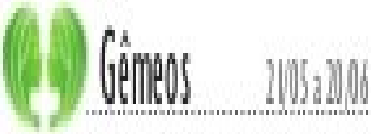

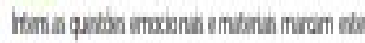

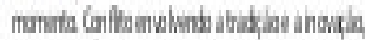

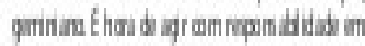

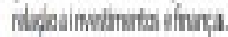

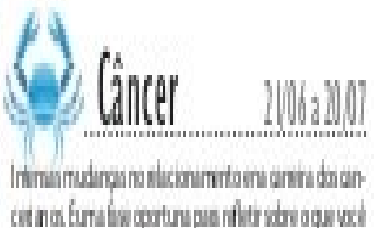

\section{Esportes:}

O caderno de esportes pode trazer não só as notícias semanais de futebol, mas também a criação de matérias que falem sobre a história e as curiosidades de cada modalidade, assim o aluno será estimulado a novos conhecimentos e quem sabe assim, surgirão interesses em praticá-los. 


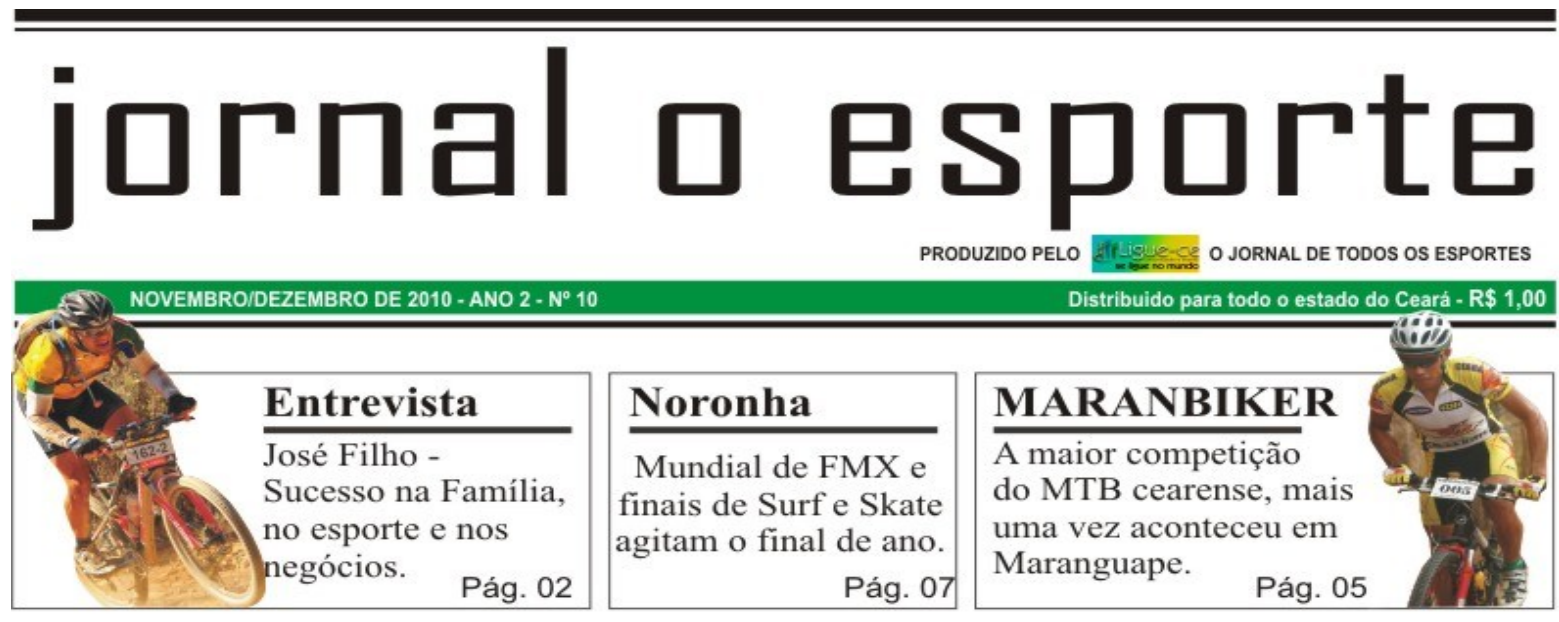

\section{O Ceará representado por 12 cearenses na Chapada da Diamantina, na maior competição Mountain Bike da história do Brasil}

6 dias de muita chuva e muita lama. $560 \mathrm{~km}$ de percurso que só foi possivel percorrer com a força que todos dávamos uns aos outros e muita força de vontade de cada um. 173 duplas estiveram presentes na largada do primeiro dia, atletas $\mathrm{r}$ e $\mathrm{n} \mathrm{o} \mathrm{m} \mathrm{a} \mathrm{d} \mathrm{o} \mathrm{s}$ internacionalmente e atletas com potencial para tornarem-se campeões mundiais nos próximos anos, atletas olímpicos e parte dos melhores atletas brasileiros.

Pág. 03

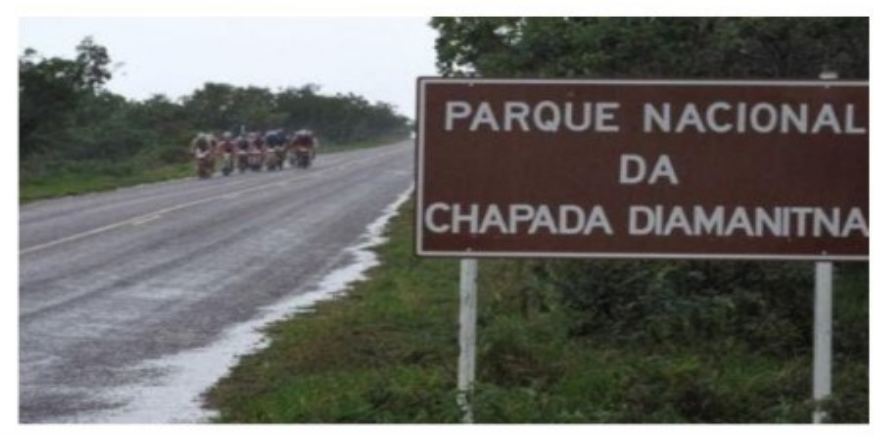

Moraisão

Pág. 10

Depois de publicarmos a história do Moraisão, seu passado, presente e futuro, descobrimos que as historias são muito mais do que as que cabiam numa só página.

\section{Marketing
Esportivo}

Entenda um pouco mais sobre Marketing e descubra as novidades do mundo globalizado. Pág. 09 seguido é o que leva ao êxito, informar todos de uma forma mesmo que saibamos das mais presente e constante. dificuldades que teremos de

Pág. 10

Figura 5 Página de Esportes

Fonte $>$ http://ligue-ce.blogspot.com.br/2010/12/jornal-o-esporte-10ed-novdez-2010-2o.html

Santos e Pinto (1992, p.7) descreve a construção do jornal escolar e seus cadernos:

O jornal escolar, juntamente com outras formas e canais de expressão pode ser um espaço importante de alunos formarem a palavra e darem a conhecer o que acham significativos ou que precisam; tornarem publicas as suas inquietações e os seus sonhos; trazerem ao debate os assuntos quentes; desenvolverem as distintas linguagens gráficas; expressarem sua capacidade e os seus gostos; exercerem a crítica e a sugestão.

Assim pode-se compreender então que a construção de cada caderno reafirma a construção do conhecimento de mundo do aluno auxiliado pelas informações relevantes do professor, em que juntos formarão um suporte informativo importante para a comunidade. 


\subsection{EIXO III: PESQUISAS E TAREFAS EM GRUPO: O PRINCÍPIO PARA O ENGAJAMENTO DO JORNAL DENTRO DA SALA DE AULA}

O papel da mídia tem sido fundamental para compreender a formação das identidades de crianças e jovens no cenário contemporâneo. Como instituições formadoras de crianças e jovens, as escolas abrem espaços para as mídias, considerando sua importância na formação das identidades dos alunos. Segundo Lopes (1989), um dos objetivos das tarefas, em situação de ensino- aprendizagem é estimular a comunicação na língua alvo, criando um propósito real para o uso da linguagem e oferecendo um contexto natural para o estudo da língua. Além disso, a ideia de tarefa e produção de gêneros textuais específicos parece se aproximar da realidade do aluno, visto que se depara diariamente com gêneros que precisam ser manipulados e produzidos, já que irá enfatizar a experiência do aprendiz além das tarefas comunicativas que podem gerar autênticos momentos de negociações entre alunos.

\subsection{EIXO IV: O PAPEL DO PROFESSOR E A CARGA AVALIATIVA}

Dentro de uma avaliação tradicional, o processo de correção do professor tem a função de prover o aluno com a correção de erros. Este erro, neste caso é considerado um desvio de norma padrão, já que se trata de um jornal que será colocado a amostra da sociedade escolar. Quanto à questão em pauta, Callado \& Estrada (1986) explanam que é comum ver no ensino tradicional, o retorno do professor com o objetivo de justificar a nota/ conceito escolar, e não com o objetivo de melhorar a sua produção escrita. É necessária a mudança deste pensamento retroativo, passando a valorizar o processo de construção do conhecimento como um todo, através da análise e discussão sobre todos os assuntos abordados (textos coesos, coerentes, reflexivos e críticos).

Continuando neste pensamento, Callado \& Estrada (1986) ressaltam também que o professor deve ser um mediador de ações, de maneira a permitir aos alunos o gerenciamento de seu próprio processo de aprendizagem. Concluindo esse pensamento, o professor dever ser reflexivo, de modo a promover a junção dinâmica entre pensamento e ação, visto que essa reflexão pressupõe ponderações quanto a praticas pedagógicas do próprio docente. Um aspecto importante a ser considerado é o ambiente escolar, o qual deve ser um lugar onde todos aprendam juntos, numa relação dialética de verdades em construção. E por fim, estimular a criatividade e incentivar ao aluno a aprender mais. 
Pontual (1999) deixa claro o comentário acima quando ressalta:

Todo professor por ser um construtor de autoestima de seus alunos, quando os ajuda a estabelecer suas metas e mostra caminhos para cumpri-la, quando sabe valorizá-los bem mais como pessoas que simplesmente como alunos. Alunos erram ou acertam, cumprem ou descumprem e para isso necessitam ser notificados, mas pessoas amam, sofrem, esperam, anseiam, alegram-se, emocionam-se e esses sentimentos necessitam de percepção e condução.

$\mathrm{O}$ aluno que tem sua autoestima elevada acaba desenvolvendo um bom trabalho em sala de aula e, consequentemente, tornar-se-á um aluno mais crítico.

\section{CONSIDERAÇÕES FINAIS}

A utilização do recurso jornal em sala de aula como recurso pedagógico, poderá contribuir de forma concreta na melhoria da leitura e escrita, a interpretação de assuntos tratados sob uma visão reflexiva. Reitera-se ainda a confirmação de que a sua prática dentro da sala de aula consegue desempenhar um papel relevante, quanto ao estímulo da leitura e melhor escrita, além da criação do interesse dentro do gênero textual Jornal.

A falta de hábito pela leitura e construção de textos sem objetivo, junto com a falta de um veículo de comunicação local para divulgar na escola, que envolvessem leituras interessantes e textos diversos produzidos pelos discentes, surgiu à preocupação e a necessidade de valorizar as produções escolares totalmente estruturadas como um Jornal, ensinando aos alunos os vários gêneros textuais e tipos existentes, trabalhando suas particularidades e com o intuito de desenvolver a formação do pensamento crítico, através da leitura transportada pela escrita para as páginas desse meio de comunicação tanto em forma de mural quanto impresso. Espera-se que quando colocado em prática, aconteça uma integração entre a escola e a comunidade escolar. Em que esses alunos possam ter mais interesse na leitura e consequentemente a melhora da escrita, buscando dominar as tipologias textuais presentes neste tipo de mídia.

Esta pesquisa tem como meta, a criação de um projeto que futuramente será levado em prática na sala de aula com o intuito de desenvolver a construção desse projeto dentro do gênero textual: O Jornal, estudando suas características, riquezas de detalhes e o possível envolvimento dos leitores com esse tipo de mídia. Visando reverter à postura passiva dos leitores (alunos) de apenas receberem as notícias, estimulando-os de todas as formas a usarem sua opinião e conhecimento a favor de um pensamento crítico. 
Todo o conceito estudado durante a pesquisa detecta a necessidade de criação de meios que favoreçam a criatividade na produção artigos de opinião sobre problemas da comunidade escolar e assuntos relevantes quanto à família, trabalho e outras formas de incentivos para jovens e adultos conseguirem também finalizarem seus estudos mesmo diante de inúmeras dificuldades que estes passam como exemplo suas rotinas diárias: trabalho em tempo integral - estudos noturnos - obrigação com sua família. O trabalho com o jornal representa de certa forma, o momento histórico-social e por isso, deverá ser estimulado em projetos de sala de aula, não se devendo fechar em opiniões, mas com a possibilidade de levar o aluno a reflexão e o questionamento.

\section{REFERÊNCIAS}

ADAIR, Flavia. O jornal como instrumento pedagógico. Programa Folha Educação: uma proposta de leitura de jornal em sala de aula. In: Comunicação \& Educação. SP: USP, jan/abr, 1995.

BAKHTIN, Mikhail Mjkhailovitch. Estética da criação verbal. 2'cd. São Paulo. Martins Fontes, 1997. (Coleção Ensino Superior)

BAZERMAN, C. Gêneros Textuais: tipificações e interação. São Paulo: Cortez Editora, 2005.

BRASIL. Parâmetros curriculares nacionais: Língua Portuguesa: Ensino de primeira à quarta série. Secretaria de Educação Fundamental. - Brasília: 1997.

CAllado, Ana Arruda; ESTRADA, Maria Ignez Duque. Como se faz um jornal comunitário. Petrópolis: Vozes, 1986.

COSTA, Cristina. Educação, Imagem e Mídias. São Paulo. Cortez, 2005. (Coleção Ensinar e Aprender com textos, V.12).

ERBOLATO, Mário. Técnicas de codificação em jornalismo: redação, captação e edição no Jornal Diário. 5 ed. São Paulo: 1991.

FARIA. Maria Alice de Oliveira. Como usar o jornal em sala de aula. 10 ed. São Paulo. Contexto, 2006.

FERRÉS, Joan. Televisão e educação. Porto Alegre: Artes Médicas, 1996.

FREIRE, Paulo, 1921 A importância do ato de ler: em três artigos que se completam /Paulo Freire. São Paulo: Autores Associados: Cortez, 1987.

FREINET, Celéstin. O Jornal Escolar. Lisboa: Estampa 1977.

GERALDI, J.W. (org.) Prática de leitura na escola. In: Geraldi, J.W. O texto em sala de aula. São Paulo: Ática, 2001. (coleção na sala de aula). 
HERR, Nicole. Aprendendo a ler com o jornal. Belo Horizonte: Dimensão, 2001.

KLEIMAN; CAVALCANTI (orgs.). Linguística Aplicada: suas faces e interfaces. Campinas, SP: Mercado de Letras, 2007.

LOPES, Dirceu Fernandes. Jornal Laboratório: do exercício escolar ao compromisso com o público leitor. São Paulo: Summus, 1989.

LOPES-ROSSI, MAG (org.) Gêneros discursivos no ensino da leitura e produção de textos. Taubaté: Cabral Editora e Livraria Universitária, 2002.

MARCONDES, Beatriz. MENEZES, Gilda. TOSHIMITSU, Thaís. Como usar outras linguagens na sala de aula. Rio de Janeiro: Editora Ensino Contexto, 2003.

MARCUSCHI, Luiz Antônio. Gêneros Textuais: Definição e Funcionalidade. In: DIONISIO, Ângela et al. Gêneros Textuais e ensino. Rio de Janeiro: Lucerna, 2002.

MARQUES DE MELO, José. Os meios de comunicação de massa e os hábitos de leitura. In: MONTEIRO, Eduardo \& FELDMAN, Márcia. "Mídia-Educação e cidadania na era da informação". In: Revista Pátio nº9 Porto Alegre: Artmed, mai/jul 1999.

MINAYO, M. C. S., 1982. O Desafio do Conhecimento. São Paulo: Hucitec.

PAVANI, Cecília. JUNQUER, Ângela. CORTEZ, Elizena. Jornal: uma abertura para a educação. Campinas, SP. Papirus, 2007.

PONTUAL, Joana Cavalcante. O jornal como proposta pedagógica. São Paulo: Paulus, 1999.

RABACA, Carlos A.; BARBOSA, Gustavo. Dicionário de comunicação. Rio de Janeiro: Codecri, 1978.

ROJO, R.H.; CAVALCANTE, J.C.; PIO D.A. Práticas de linguagens no ensino fundamental: circulação e apropriação de gêneros do discurso e a construção do conhecimento. Intercambio São Paulo, v.10, p.125-136, 2001.

SANTOS, Antônio; PINTO, Manuel. O jornal escolar, porque e como fazê-lo. Porto Edições Asa, 1992.

TAJRA, Sanmya Feitosa. Informática na Educação: novas ferramentas pedagógicas para o professor na atualidade. São Paulo, SP. Editora: Erica 2001

TEIXEIRA, Anísio. Educação não é um privilégio. 5 ed. Rio de Janeiro: Editora UFRJ, 1994. $250 \mathrm{p}$. 